\author{
Dikla WizMAN-MaN \\ Higher Studies of Israel
}

\title{
OPTIMISTIC APPROACH TOWARDS LIFE AS A PROTECTIVE FACTOR FOR ADOLESCENTS WITH LD AND ADHD
}

\begin{abstract}
AвSTRACT. Wizman-Man Dikla, Optimistic Approach Towards Life as a Protective Factor for Adolescents with $L D$ and $A D H D$ [Optymistyczne podejście do życia jako czynnik ochronny dla nastolatków z LD i ADHD]. Studia Edukacyjne nr 48, 2018, Poznań 2018, pp. 377-391. Adam Mickiewicz University Press. ISSN 1233-6688. DOI: 10.14746/ se.2018.48.1
\end{abstract}

The objective of this study is to examine the influence of life-stories narrative intervention programs on the optimistic approach towards life of adolescents with learning disabilities (LD) and attention deficit disorders (ADHD). Changes in the optimistic approach towards life of adolescents with LD and ADHD who took part in an intervention program were compared pre-and post-program and to ordinary high school graduates who did not participate in the program. The findings indicate a significant improvement in the level of optimism pre- and post- intervention program. In addition, higher levels of optimistic approach towards life in the general index and relating to graduates' level of optimism in situations of uncertainties were reported among graduates with LD and ADHD, compared with regular high school graduates. No differences were found in other aspects of the questionnaires. Results call for further research on additional protective variables, and on the effectiveness of the intervention program in both special education and regular high schools.

Key words: adolescents with ADHD and LD, approach to life, optimism, narrative approach, narrative psychotherapy

To the question of whether I am pessimistic or optimistic, I reply that my knowledge is pessimistic, but my will and hope are optimistic

Albert Schweitzer

\section{Introduction}

Learning disabilities (LD) are an array of neurodevelopmental disorders that affect basic learning functions, which may impair a person's ability to acquire and express knowledge and skills expected of people according to age, education, and level of IQ. Coping with learning disabilities may affect 
the individual's development and functioning in all areas of life. Significant difficulties in acquiring and using learning skills carry an influence on the social, emotional, behavioral, and managerial domains. ${ }^{1}$

Protective factors for the development of psychological resilience have been identified in the research as improving the chances of people with learning disabilities to develop in a healthy manner, and realize their potential. ${ }^{2}$ Psychological resilience is a term that describes a psychological ability to cope with stress and crisis and to adapt to life circumstances caused by such situations. Mental toughness is a measure of predicting the ability to cope with potential distress. One of the personality trait variables found in high correlation with mental toughness is the tendency towards optimism. Research shows that optimism is a significant component in the positive manner of coping of those who are defined as highly resilient. This personality trait variable was found to have an influence on the mental and physical well-being of the individual, and appears to contribute to resilience as it can lead to better adaptation in stressful circumstances.

This study examines optimism approach towards life, as a predictor of protective factor ${ }^{3}$ among graduates with LD and attention deficit hyperactivity disorders (ADHD). The special education school for LD students ran a program called "Personal Development Life Stories" which was constructed based on the principles of the narrative approach.

The first part of this paper presents the definitions of LD and ADHD, the characteristics and future implications as well as risk factors for this population. Furthermore, ${ }^{4}$ Theory of Psychological resilience is discussed, as well as the personality trait variable- optimistic approach towards life as a protective factor. In the second part of this paper, the objectives, methods and findings of the study are presented, followed by a discussion of the theoretical and practical implications of the findings.

\section{Learning disabilities (LD) and attention deficit hyperactivity disorder (ADHD)}

The Diagnostic and Statistical Manual of Mental Disorders (DSM-5, 2013) defines learning disability as a neurodevelopmental disorder with a biologi-

\footnotetext{
${ }^{1}$ American Psychiatric Association (APA), DSM-5, A Diagnostic and Statistical Manual of Mental Disorders, 5th edition, American Psychiatric Association, Washington DC 2013.

${ }^{2}$ Y. Sulimani-Aidan, R. Benbenishty, Future expectations of adolescents in residential care in Israel, Children and Youth Services Review, 2011, 33.

${ }^{3}$ C. Evangelos, K. Konstantinos, D. Georgios, Optimism, Self-efficacy and Information Processing of Threat and Well Being Related Stimuli, Stress and Health, 2007, 23.

${ }^{4}$ G.M. Morrison, M.A. Cosden, Risk, Resilience, and Adjustment of Individuals with Learning Disabilities, Learning Disability Quarterly, 1997, 20.
} 
cal basis and cognitive implications. The biological background is expressed in the interaction between genetic and environmental factors that influence the ability of the brain to function efficiently and accurately in cognitive activities, such as perception and the processing of verbal and nonverbal information. It is an ongoing disorder that affects learning functions, such as reading, reading comprehension, written expression, spelling, mathematical calculations, and mathematical logic, and is manifested in varying degrees of severity (severe, moderate, and light).

Among the literature for the concept of learning disabilities, there are references to difficulties in activity and participation in a variety of areas of life, not only in the areas of learning. For example, in 1985, the American Learning Disabilities Association (LDA) defined learning disabilities as a chronic condition manifested in various expressions and levels of severity that may affect self-esteem, academic achievement, as well as work and day-to-day functioning. ${ }^{5}$ In 2002, Canada's Learning Disabilities Foundation further stated that learning disabilities can also lead to difficulties in organizational skills, perception, social interactions and perceptions of life, and that the manifestations of learning disabilities may change throughout the course of life and are influenced by interactions between the environment's demands and the forces and needs of the person with learning disabilities. ${ }^{6}$

The definition refers to findings on the high prevalence of LD and other neurodevelopmental impairments, such as attention deficits disorder and hyperactivity, communication impairments, coordination impairments, and impairments in the range of autism, as well as a shared presence with other mental disabilities: anxiety, depression and bipolar disorder. Furthermore, a review of the literature presents consistent findings emphasizing that in addition to cognitive difficulties, children with LD express a variety of social, emotional and behavioral difficulties. ${ }^{7}$ Children may express a high level of social withdrawal, anxiety, depression, feelings of loneliness, low levels of

${ }^{5}$ L.K. Elksnin, N. Elksnin, The Social-Emotional Side of Learning, Etiology, Assessment, and Treatment, [in:] Touching beyond the Armor: Conversation between the Internal World and the Life Cover of the Student with Attention Deficit Hyperactivity Disorder, Ministry of Education Press, 2004.

${ }^{6}$ LDA Canada (Learning Disabilities Association of Canada), Official Definition of Learning Disabilities, 2002, Available at http:www.ldac-acta.ca/learn-more/ld-defined/a-working-description-of-learning-disabilities.

${ }^{7}$ M. Al-Yagon, M. Mikulincer, Patterns of Close Relationships and Socioemotional and Academic Adjustment among School-Age Children with Learning Disabilities, Learning Disabilities Research and Practice, 2004, 19(1) Socioemotional and Academic Adjustment among Children with Learning Disorders: The Meditational Role of Attachment Based Factors, Journal of Special Education, 2004, 38; T. Lackaye et al., Comparisons of Self-Efficacy, Mood, Effort, and Hope between Students with Learning Disabilities and Their Non-LD-Matched Peers, Learning Disabilities Research \& Practice, 2006, 21(2); M. Margalit, Loneliness, the Salutogenic Paradigm and Learning Disabilities: Current Research, Future Directions, and Interventional Implications, The Cruickshank Memorial Lecture, Thalamus, 2006, 24(1). 
coherent feelings and low self-esteem compared to children without disabilities, ${ }^{8}$ and develop feelings of frustration because of their lack of success in the scholastic and social fields, which leads to a feeling of personal failure and alienation towards a society that does not except them. Moreover, there is a gap between the individual's potential and actual achievements, which may lead to school drop-out, unemployment, criminal activity, marital problems, medical, psychological and physical problems. Einat and Einat, ${ }^{9}$ found that LD and ADHD constitute two significant risk factors for future delinquency behavior, and that there is a possible causal relationship between the former and such kind of behavior

ADHD is a neurodevelopmental disorder ${ }^{10}$ that results from a combination of genetic factors, forming a significant part in the development of the disorder, and environmental factors (e.g. drug consumption or heavy smoking of the mother during pregnancy). Typical clinical signs of this disorder may appear already at the age of three or four. According to the DSM-IV-TR (2000), ADHD is defined as a disorder that includes impaired attention, impulsive behavior, and hyperactivity. The definition includes two categories of criteria - a category of attention deficits that define attention deficit disorder (ADD) and a category of hyperactivity and impulsivity that define Attention Deficit Hyperactivity Disorder (ADHD).

ADHD is manifested in poor judgment about the proper behavior in a particular social and/or emotional state. The disorder is also characterized by restlessness, lack of discipline, lack of concentration, the unwillingness or lack of ability to complete tasks, difficulty in obeying laws, and inability to assess dangers for themselves or others. At school age, the disorder may be characterized by low grades, difficulties in organizing and avoiding homework. The disorder may result in dropping out of the school framework and even in a difficulty in finding employment among adolescents.

The proportion of school-age children suffering from ADHD in the US is $3-7 \%$ (DSM-IV, 2000), ${ }^{11}$ and Israel, it is estimated at 5\% -10\% of the total school-age population. ${ }^{12}$ The main age of diagnosis is primary school age, in which the disorder is expressed in full due to the educational and social requirements.

${ }^{8}$ M. Al-Yagon, M. Mikulincer, Patterns of Close Relationships; W.N. Bender, M.E. Wall, Social Emotional Development of Students with Learning Disabilities, Learning Disability Quarterly, 1994, 17; T. Lackaye, M. Margalit, Comparisons of Achievement, Effort and Self-Perceptions among Students with Learning Disabilities and Their Peers from Different Achievement Groups, Journal of Learning Disabilities, 2006, 39(5).

9 A. Einat, T. Einat, Indictment: learning disabilities, dropping out and delinquency, The United Kibbutz Movement, 2007.

10 A. Or-Noy, Attention Deficit Disorders with or without Hyperactivity, 2009.

${ }_{11}$ S. Ozdemir, A Comparison of Problem Behavior Profiles in Turkish Children with AD/HD and non-AD/HD Children, Electronic Journal of Research in Education and Psychology, 2010, 8(1).

${ }^{12}$ Ministry of Health, Ministry of Health Circular, 2010/40, File 2/14. 
Two-thirds of the children continue to suffer from ADHD even in adulthood, although hyperactivity declines. In one-third of the children there is a partial or complete decline of the disorder as a whole (Manor \& Tiano, 2004).

Emotional instability has been associated with increased severity of symptoms of hyperactivity, especially hyperactivity and impulsivity, ${ }^{13}$ and many studies link ADHD with the risk of varied emotional problems such as depression, anxiety, Irritability, alienation, and extreme mood changes that do not suit the situation and the child's age. Moreover, according to the Association of Child and Adolescent Psychiatry in Israel, 15-75\% of children with ADHD also suffer from mood disorders such as co-morbid. Depression, for example, is found in $25 \%$ of children with ADHD, compared with $5-10 \%$ of the general population.

Social relationships pose another challenge for children with ADHD as they are likely to display inadequate social skills, limited and inaccurate perceptions of social codes, and lack of attention to emotional information from the environment. ${ }^{14}$ ADHD children find it difficult to develop and maintain positive relationships with peers and adults, and to initiate social communication. Many have difficulties in relationships with authority figures and within the family framework (Shechtman, 2010).

\section{Psychological resilience and defensive factors}

According to Seginer, ${ }^{15}$ the future is often associated with positive and optimistic thinking. However, assessing the future as positive requires thinking about the future and such thinking is only possible when the person is equipped with personal resources that include personal traits and personal skills that enable investment in the challenges of the present and in the challenges of the future. Psychological resilience or mental toughness are terms that describe a psychological ability to deal with stress and crisis and adapt to life circumstances caused by stressful situations. Psychological resilience is also a predictive personality indicator for the ability to cope with future distress.

According to the American Psychological Association (APA) (2009), mental strength is not an innate trait, but rather a mixture of thoughts, behaviors,

${ }^{13}$ E. Sobanski et al., Emotional Lability in Children and Adolescents with Attention Deficit/Hyperactive Disorder (ADHD): Clinical Correlates and Familial Prevalence, Journal of Child Psychology and Psychiatry, 2010, 51(8).

${ }^{14}$ R.A. Barkley, Attention - Deficit Hyperactivity Disorder: A Handbook for Diagnosis and Treatment, 3rd edition, New York 2006; S.H. McConaughy et al., Academic and Social Impairments of Elementary School Children with Attention Deficit Hyperactivity Disorder, School Psychology Review, 2011, 40(2).

${ }^{15}$ R. Seginer, Mental Distress, Personal Resources, and Developmental Tasks: Personality Correlates of Future Orientation of Adolescents, Studies in Education, 2016, 25. 
and actions that can be learned and developed in every person. Lahad ${ }^{16}$ defines mental toughness as the sum of all the individual efforts to meet life. It is the ability for self-recovery, with the help of others or through other means, despite the difficulties.

A protective factor is a mediator that strengthens and enhances mental toughness in dealing with the effects of risk factors to reduce, or eliminate them. The significance of the defense is to expand the responses of Psychological resilience during exposure to risk situations. ${ }^{17}$ Edelstein and Cohen ${ }^{18}$ note that defense factors are perceived as factors that express hope, optimism, and internal resources of the individual, enabling better coping in the present and providing an optimistic and positive outlook of the future. Studies in children and adolescents at risk show that adolescents' future expectations may affect their motivation and ability to achieve their goals successfully, immediately after leaving the education system and years later as adults. Positive expectations for the future were found to protect and promote resilience, social adjustment, and mental well-being. ${ }^{19}$

\section{Personality trait variable - optimistic approach towards life}

Optimism is a personality trait variable that reflects the extent to which people hold generalized favorable expectancies for their future. Higher levels of optimism have been related prospectively to better subjective well-being in times of adversity or difficulty. Consistent with such findings, optimism has been linked to higher levels of engagement-coping and lower levels of avoidance, or disengagement-coping. Scheier and Carver ${ }^{20}$ describe optimi$\mathrm{sm}$ as a generalized tendency to expect positive outcomes even in the face of obstacles. Buchanan and Seligman ${ }^{21}$ describe optimism in terms of how people explain bad events in their past. The extent to which people tend to be optimistic varies across individuals. Additionally, situational factors influence optimism. Optimistic individuals believe they can overcome obstacles and perceive difficult tasks as challenges rather than threats. Optimism stimulates persistence in goal pursuit and enhances psychological and physical adjust-

${ }^{16}$ M. Lahad, Fantastic Reality and Creative Therapy Training, Haifa 2006.

17 R.J. Haggerty et al., Stress, risk, and resilience in children and adolescents: Processes, mechanisms, and interventions, Cambridge 1994.

18 A. Edelstein, S. Cohen, Risk factors and protective factors for suicidal behavior among Ethiopian-Israeli youth. From disconnection to integration, 2008, 15.

19 Y. Sulimani-Aidan, R. Benbenishty, Future expectations of adolescents in residential care in Israel, Children and Youth Services Review, 2011, 33.

${ }^{20}$ M.F. Scheier, C.S. Carver, Optimism, coping and health: assessment and implications of generalized outcome expectancies, Health Psychology, 1985, 4.

${ }^{21}$ G. Buchanan, M.E.P. Seligman, Explanatory style, Hillsdale, New York 1995. 
ment to stressful events. ${ }^{22}$ Furthermore, there is strong link between optimism and psychological well-being. Studies of children and adolescents at risk consistently note optimism about the future as one of the contributing factors to resilience. ${ }^{23}$ Optimism helps change the perception of stressful events and turn them into opportunities for personal growth and development. ${ }^{24}$

\section{Narrative approach - narrative as a therapeutic tool}

The therapeutic work of narratives, especially life stories, occupies today an important role in various fields - medicine, law, psychology and education. The basic assumption is that humans are by nature story tellers, and that their stories express their identity. The story is a raw material for self-observation and the creation of a new story. Through the story the narrator explains to himself and to others his doings, and rebuilds his identity. The narrative as the common way for people to summarize their experiences in daily life, to create continuity between them and to give them meaning.

The narrative is a basic form of searching for meaning. Shalsky and Alpert $^{25}$ define narrative as a developing, beginning, middle, and end-centered narrative rooted in some context. We do not allow events in our lives to remain isolated to themselves, but insist on arranging our experiences into logical sequence, with logical rules of 'cause' - 'explanation' and 'result'. Therefore, as we look back in time, we find that our lives are composed of stories with a clear and structured narrative sequence. This continuum continues to evolve and changes over time, causing our memories to change and be rebuilt at every moment, according to our current experiences.

\section{Research results}

Approximately 344,000 children and youth are at risk in Israel. 34\% of the children and youth at risk are suffering from various disabilities. In recent years, efforts were devoted to the introduction of structural changes in order to strengthen the ability of schools to provide solutions to these students. Emphasis is placed on developing a sense of belonging in the school, self-image

${ }^{22}$ C.S. Carver et al., Optimism, Clinical Psychology Review, 2010, 30

${ }^{23}$ P. Boman, D.C. Smith, D. Curtis, Effects of pessimism and explanatory style on development of anger in children, School Psychology International, 2003, 24.

${ }^{24} \mathrm{M}$. Marom, Chronic and disturbing pressures, and critical life events as predictors of mental health and a process of leaning an organization among new workers: the mitigating effect of mental strength and social support, Bar Ilan University 1999.

${ }^{25} \mathrm{~S}$. Shalsky, B. Alpert, Ways to write qualitative research. From the dissolution of reality to its construction as text, Mofet Institute 2007. 
and self-efficacy of students. ${ }^{26}$ Moreover, the implementation of different work strategies in the classroom, has been given priority. However, researchers claim that many schools in Israel are based on the normative-medical approach. According to this approach the goal is to bring students with disabilities closer to performance levels that meet normative standards, and less to focus on achieving a positive inner experience. ${ }^{27}$ In addition, despite recent years policy changes, the Israeli education system tends to prefer segregation that includes the classification of children with "disabilities" and their placement into special frameworks, rather than integrating them into existing frameworks.

The purpose of this study is to examine whether there is a change in the level of optimistic approach towards life of graduates with LD and ADHD as a result of their participation in an intervention program. An additional purpose is to examine the variance in the personality trait variable- optimistic approach towards life between school graduates with LD and ADHD for school graduates who completed regular high school. A positive change is expected for graduates with LD and ADHD upon completion of the intervention program, in comparison with ordinary school graduates.

\section{Research population}

The research population consists of 20 students who completed their studies in a special education school for students with multidimensional LD and attention disorders and 74 ordinary high school graduates. Special education students took part in a three or four-year program called "Personal Development Life Stories". The intervention program was written on the basis of the principles of the narrative approach, with the intention of enabling the students to discuss and cope with life stories through the use of diverse narrative tools, different universal themes and developmental themes that correspond to the students' ages. All the students were required to take part in the program meetings, which took place every week for two hours.

\section{Research tools}

Questionnaire were distributed among participants. The questionnaire was compiled by Scheier \& Carver $^{28}$ and designed to test a general sense of optimism. It consists of six items on a 5-step Likert scale ranging from 1 ("strongly disagree") to 5 ("Agree to a very large extent"). The questionnaire

${ }^{26}$ M. Zeidner, Effective indicators in educational environments, [in:] Guidelines for Renewal of Education Indicators in Israel, Eds. M. Justman, G. Bukobza, Jerusalem 2010.

27 A. Hass, Types of responses, adaptation and coping of students with visual impairments, for inclusion in schools, Negev 2006.

${ }^{28}$ M.F. Scheier, C.S. Carver, Optimism, coping and health. 
was adjusted for the study, the scale changed between 3 levels. The questionnaire was found to have a validated structure and validity. ${ }^{29}$

\section{Process}

LD and ADHD graduates underwent a narrative interview and answered a questionnaire. The questionnaire was filled twice, with reference to two different points in time: prior to participating in the intervention program and upon completion of the program and school. Concurrently, the questionnaire was submitted via Google docs to 74 ordinary high school graduates who did not join the program.

\section{Results}

In order to compare the reporting of graduates with LD and ADHD on the personality trait variable- optimistic approach towards life, a t-test was conducted for dependent variables. The test compared optimistic approach in retrospective reporting to the period prior to the intervention program and after program completion and graduation. The results of the t-test showed a significant change in the overall indices, both in the general index and in the overall items in the questionnaire that examined the index. In other words, the graduates reported higher levels of optimistic approach towards life after their integration into the intervention program. For details of the results see Table 1 and Figure 1.

Table 1

Results of t-tests for measuring the approach to optimistic approach towards life before (retrospective) and after the intervention program in graduates with LD and ADHD

\begin{tabular}{|l|c|c|c|c|c|}
\hline \multirow{2}{*}{} & \multicolumn{2}{|c|}{ Past } & \multicolumn{2}{c|}{ Present } & $\mathrm{T}$ \\
\cline { 2 - 6 } & Mean & St.d & Mean & St.d & $(\mathrm{df}=15)$ \\
\hline General & 1.63 & .47 & 2.52 & .52 & $4.88^{* * *}$ \\
\hline $\begin{array}{l}\text { Expecting for good } \\
\text { in uncertainty }\end{array}$ & 1.56 & .63 & 2.63 & .62 & $4.58^{* * *}$ \\
\hline Expecting for good & 1.50 & .52 & 2.31 & .79 & $3.31^{* *}$ \\
\hline $\begin{array}{l}\text { Things get along } \\
\text { as expected }\end{array}$ & 1.56 & .81 & 2.38 & .62 & $3.31^{* *}$ \\
\hline Will be good & 1.88 & .62 & 2.75 & .58 & $4.34^{* *}$ \\
\hline
\end{tabular}

${ }^{* *} \mathrm{p}<.01,{ }^{* * *} \mathrm{p}<.001$.

${ }^{29}$ K.L. Burke et al., An investigation of concurrent validity between two optimism/pessimism questionnaires: The life orientation test-revised and the optimism/pessimism scale, Current Psychology, 2000, 19 . 


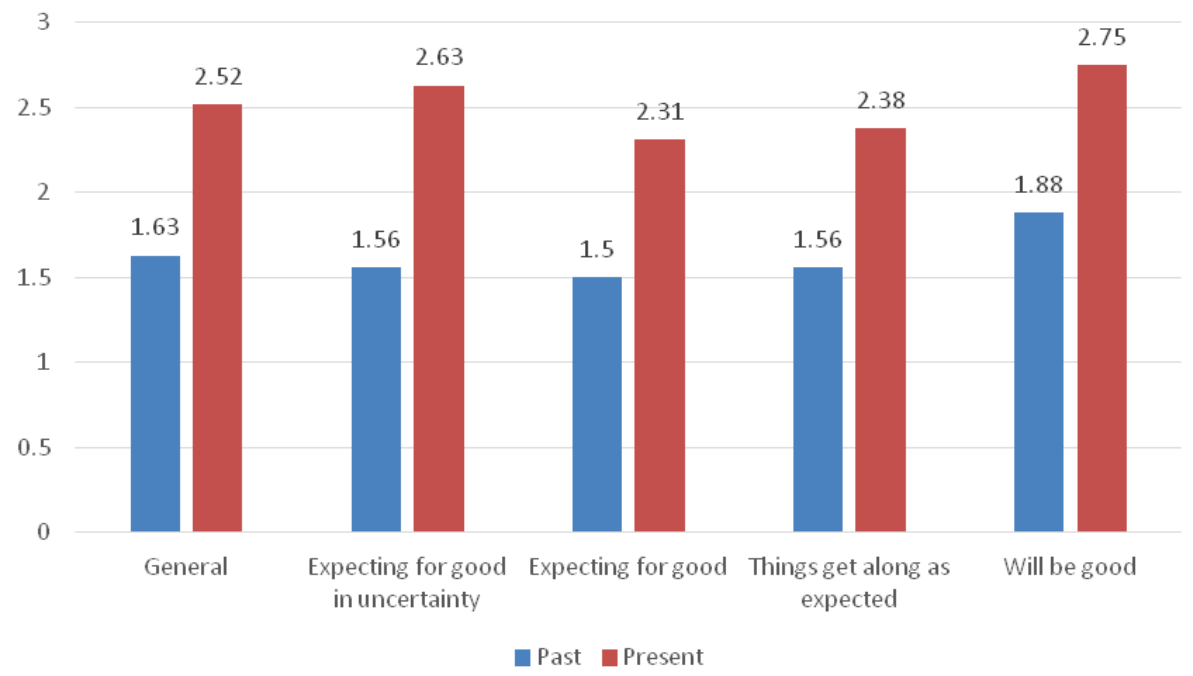

Fig. 1. Results of t-tests for measuring optimistic approach towards life - retrospective and after intervention among graduates with LD and ADHD

To compare results between graduates with LD and ADHD who participated in the intervention program and regular students who did not participate in the intervention program, a t-test was conducted for dependent variables. The results are significant in the reporting higher levels of optimistic approach towards life among graduates with LD and ADHD, compared to regular high school graduates, both in the general index and in the first statement: "In periods of uncertainty, For the best".

In items 4,5,6 no differences were reported between the two groups. Intercorrelation between the questions (low Cronbach). The general index was calculated as an average of all four questions together.

Table 2 Comparison of Personality trait variable life - Optimistic approach towards life among graduates with LD and ADHD who participated in the intervention program and regular high school graduates who did not participate in the program

\begin{tabular}{|l|c|c|c|c|c|}
\hline \multirow{2}{*}{} & \multicolumn{2}{|c|}{$\begin{array}{c}\text { Non LDs } \\
(\mathrm{n}=74)\end{array}$} & \multicolumn{2}{c|}{$\begin{array}{c}\text { LDs } \\
(\mathrm{n}=16)\end{array}$} & $\mathrm{T}$ \\
\cline { 2 - 6 } & Mean & St.d & Mean & St.d & $(\mathrm{df}=88)$ \\
\hline General & 2.31 & .32 & 2.52 & .52 & $2.02^{*}$ \\
\hline $\begin{array}{l}\text { Expecting for good in } \\
\text { uncertainty }\end{array}$ & 2.11 & .56 & 2.63 & .62 & $3.27^{* *}$ \\
\hline
\end{tabular}




\begin{tabular}{|l|c|c|c|c|c|}
\hline Expecting for good & 2.07 & .69 & 2.31 & .79 & 1.26 \\
\hline $\begin{array}{l}\text { Things get along as } \\
\text { expected }\end{array}$ & 2.49 & .50 & 2.38 & .62 & .77 \\
\hline Will be good & 2.60 & .64 & 2.75 & .58 & .90 \\
\hline
\end{tabular}

${ }^{*} \mathrm{p}<.05,{ }^{* *} \mathrm{p}<.01$

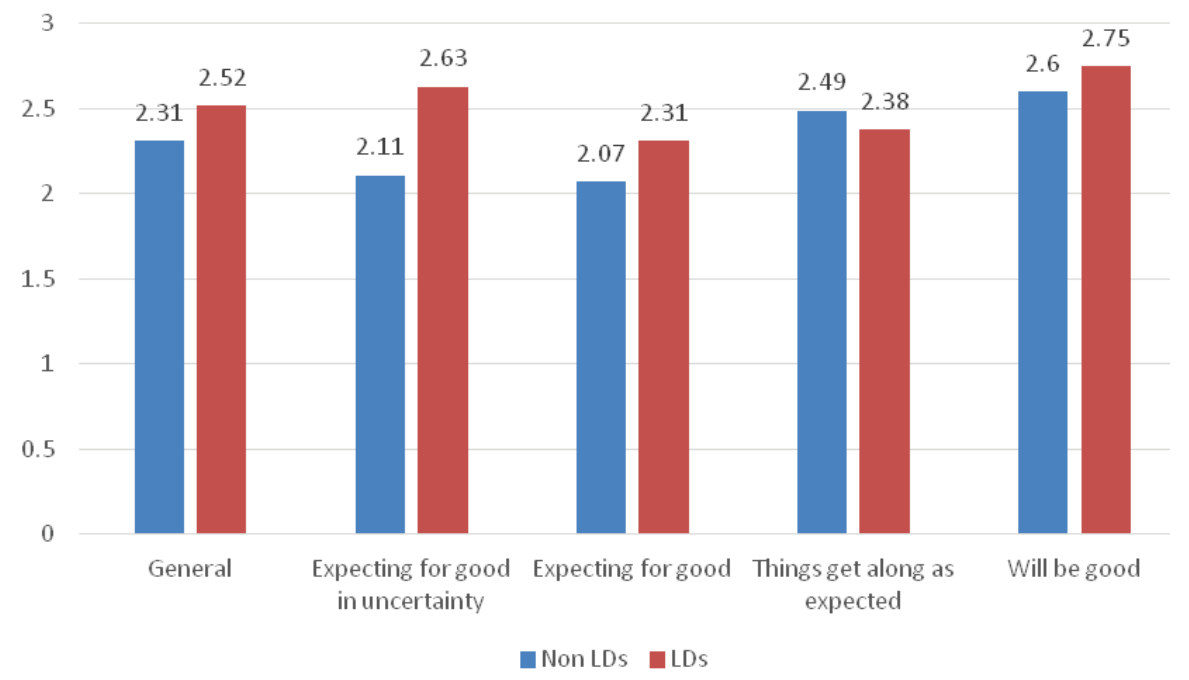

Fig. 2. Comparison of optimistic approach towards life between graduates with LD and ADHD who participated the intervention program and regular high school graduates who did not participate in the intervention program

\section{Discussion}

This study examines the internal world of high school graduates with LD and ADHD as part of a broader follow-up study, with a specific reference to a personality trait variable, optimistic approach towards life, as a protective factor. The goal of the study was to evaluate the effectiveness of the intervention program in increasing the levels of optimistic approach towards life of graduates with LD and ADHD. A further aim was to compare levels of optimism between graduates with LD and ADHD and regular school graduates. The main hypothesis of a positive change after participation in the intervention program was clearly confirmed. An increase was identified in the optimism levels among adolescents with LD and ADHD who have participated in the intervention program. 
How can this significant change be explained? One possibility is to focus the change on the essence, the theoretical rationale, and the unique elements of the intervention program. The program was based on the principles of the narrative approach, ${ }^{30}$ enabling interaction and discussion of the personal narrative, its development and its change, as well as the expansion of the stories and the creation of an identity with an optimistic approach that may predict resilience in the future. ${ }^{31}$ This explanation can shed light and allow us to re-examine the impact of other intervention programs. Findings may point to the program's effectiveness. It is therefore important to elaborate and deepen the examination of more LD and ADHD adolescents over several years and examine long-term self-efficacy. In addition, the program's influence on additional protective variables, such as: self-image, future orientation, ability, etc. should be analyzed.

The second hypothesis related to the differences between two populations: graduates with $\mathrm{LD}$ and $\mathrm{ADHD}$, who took part in the program, the other, regular graduates who did not participate in the program. The findings show a significance in the general index and in the statement "In situations of uncertainty I expect the best." In other words, graduates with LD and ADHD reported higher levels of optimistic approach towards life, strengthening the hypothesis regarding the influence of the program. This is even more surprising because at the time of the evaluation, these graduates were at a stage of transition between a known, familiar and safe system to the unknown future, and yet there were clear indications of an optimistic approach towards the future and its uncertainty. Findings also correspond with other data that attest to the adequacy of the additional indices in the questionnaire between the two populations examined. This preliminary study raises a new discussion of the nature of existing intervention programs for LD and ADHD populations and their long-term effects on the life of these youth.

\section{Conclusions and practical implications}

In this study, significant changes were found in graduates' optimistic approach to life. Study findings are consistent with resilience theories that stress the connection between personality traits and the ability to cope with major objective difficulties. Optimism is a significant component in the coping manner of those defined as highly resilient, as it helps to transform stressful

${ }^{30}$ M. White, Maps of Narrative Practice, New York - London 2007.

${ }^{31}$ G.M. Morrison, M.A. Cosden, Risk, Resilience, and Adjustment of Individuals with Learning Disabilities, Learning Disability Quarterly, 1997, 20. 
events into opportunities for growth and personal development. ${ }^{32}$ Educational frameworks should encourage therapeutic educational process that enables adults to voice their stories, increase their self-awareness and build a life story based on an optimistic approach towards the future. It is the author's sincere hope that this preliminary study will promote the rethinking of therapeutic educational processes for adolescents with $\mathrm{LD}$, that are so necessary and inseparable from their future lives and success.

\section{Research limitations}

This study provides an initial source for a more in-depth observation of youth with LD and ADHD in their final high school stages. Furthermore, the study focuses on the protective variable optimistic approach towards life. However, some consideration should be given to the limitations of the study. At first, it should be pointed out that evaluation took place only once, while requiring the population of subjects to reconstruct a second point in time from the past prior to entering the program. A longitudinal study that stretches even after graduates leave the educational system to an independent life, may provide more insight to questions such as whether optimism is indeed predictive of resilience. At the same time, it is important to note that the assessment of this variable for younger ages, may pose some challenge as the future may seem too far away to obtain reliable results.

A further limitation is caused by the sampling method - the number of subjects was different between the populations - graduates with LD and ADHD were interviewed in a narrative in-depth interview and it was necessary to mediate questionnaires due to learning disabilities. As a result of described time limitations, the sample population was narrowed to 20 graduates. Process for the regular high school graduates was shorter enabling a population sample of 74 graduates.

\section{BIBLIOGRAPHY}

Administration of Medicine, Department for Health Issues, Ministry of Health. (Hebrew). Al-Yagon M., Mikulincer M., Patterns of Close Relationships and Socioemotional and Academic Adjustment among School-Age Children with Learning Disabilities, Learning Disabilities Research and Practice, 2004, 19(1).

Al-Yagon M., Mikulincer M., Socioemotional and Academic Adjustment among Children with Learning Disorders: The Meditational Role of Attachment Based Factors, Journal of Special Education, 2004, 38.

${ }^{32}$ M. Marom, Chronic and disturbing pressures. 
American Psychiatric Association (APA), DSM IV-TR, A Diagnostic and Statistical Manual of Mental Disorders, 4th edition, American Psychiatric Association, Washington DC 2000.

American Psychiatric Association (APA), DSM-5, A Diagnostic and Statistical Manual of Mental Disorders, 5th edition, American Psychiatric Association, Washington DC 2013.

APA, The Road to Resilience, 2009, [Retrieved: 20.09.11] from http://www.apahelpcenter. org/featuredtopics / feature.php?id=6\&ch=1

Barkley R.A., Attention - Deficit Hyperactivity Disorder: A Handbook for Diagnosis and Treatment, 3rd edition, Guilford Press, New York 2006.

Bender W.N., Wall M.E., Social Emotional Development of Students with Learning Disabilities, Learning Disability Quarterly, 1994, 17.

Boman P., Smith D.C., Curtis D., Effects of pessimism and explanatory style on development of anger in children, School Psychology International, 2003, 24.

Buchanan G., Seligman M.E.P., Explanatory style, Hillsdale, Erlbaum, New York 1995.

Burke K.L., Joyner A.B., Czech D.R., Wilson M.J., An investigation of concurrent validity between two optimism/pessimism questionnaires: The life orientation test-revised and the optimism/pessimism scale, Current Psychology, 2000, 19.

Carver C.S., Michael F., Scheier B., Segerstrom S.C., Optimism, Clinical Psychology Review, 2010, 30.

Disabilities, Learning Disability Quarterly, 27(1).

Edelstein A., Cohen S., Risk factors and protective factors for suicidal behavior among Ethiopian-Israeli youth. From disconnection to integration, 2008, 15.

Einat A., Einat T., Indictment: learning disabilities, dropping out and delinquency, The United Kibbutz Movement, 2007.

Elksnin L.K., Elksnin N., The Social-Emotional Side of Learning, Etiology, Assessment, and Treatment, [in:] Touching beyond the Armor: Conversation between the Internal World and the Life Cover of the Student with Attention Deficit Hyperactivity Disorder, Ministry of Education Press, 2004. (Hebrew).

Evangelos C., Konstantinos K., Georgios D., Optimism, Self-efficacy and Information Processing of Threat and Well Being Related Stimuli, Stress and Health, 2007, 23.

Haggerty R.J., Sherrod L., Garmezy N., Rutter M., Stress, risk, and resilience in children and adolescents: Processes, mechanisms, and interventions, Cambridge University Press, Cambridge, UK 1994.

Hass A., Types of responses, adaptation and coping of students with visual impairments, for inclusion in schools, Research for the degree of Doctor of Philosophy, Submitted to the Senate of Ben-Gurion University of the Negev 2006.

Lackaye T., Margalit M., Comparisons of Achievement, Effort and Self-Perceptions among Students with Learning Disabilities and Their Peers from Different Achievement Groups, Journal of Learning Disabilities, 2006, 39(5).

Lackaye T., Margalit M., Ziv O., Ziman T., Comparisons of Self-Efficacy, Mood, Effort, and Hope between Students with Learning Disabilities and Their Non-LD-Matched Peers, Learning Disabilities Research \& Practice, 2006, 21(2).

Lahad M., Fantastic Reality and Creative Therapy Training, Nord, Haifa 2006.

LDA Canada (Learning Disabilities Association of Canada), Official Definition of Learning Disabilities, 2002, Available at http:www.ldac-acta.ca/learn-more/ld-defined/a-working-description-of-learning-disabilities.

Margalit M., Loneliness, the Salutogenic Paradigm and Learning Disabilities: Current Research, Future Directions, and Interventional Implications, The Cruickshank Memorial Lecture, Thalamus, 2006, 24(1). 
Marom M., Chronic and disturbing pressures, and critical life events as predictors of mental health and a process of leaning an organization among new workers: the mitigating effect of mental strength and social support, Dissertation, Department of Psychology, Bar Ilan University 1999.

McConaughy S.H., Volpe R.J., Antshel K.M., Gordon M., Eiraldi R.B., Academic and Social Impairments of Elementary School Children with Attention Deficit Hyperactivity Disorder, School Psychology Review, 2011, 40(2).

Ministry of Health, Ministry of Health Circular, 2010/40, File 2/14.

Morrison G.M., Cosden M.A., Risk, Resilience, and Adjustment of Individuals with Learning Disabilities, Learning Disability Quarterly, 1997, 20.

Or-Noy A., Attention Deficit Disorders with or without Hyperactivity, 2009.

Ozdemir S., A Comparison of Problem Behavior Profiles in Turkish Children with AD/HD and non-AD/HD Children, Electronic Journal of Research in Education and Psychology, 2010, 8(1).

Scheier M.F., Carver C.S., Optimism, coping and health: assessment and implications of generalized outcome expectancies, Health Psychology, 1985, 4.

Scheier M., Carver C., Bridges M., Optimism, Pessimism and Psychological Well-Being, [in:] Optimism \& Pessimism Implications for Theory, Research and Practice, Ed. E.C. Chang, American Psychological Association, Washington DC 2001.

Seginer R., Mental Distress, Personal Resources, and Developmental Tasks: Personality Correlates of Future Orientation of Adolescents, Studies in Education, 2016, 25 (Hebrew).

Shalsky S., Alpert B., Ways to write qualitative research. From the dissolution of reality to its construction as text, Published by the Mofet Institute 2007.

Sobanski E., Banachewski T., Asherson P., Buitelaar J., Chen W., Franke B., Holtmann M., et al., Emotional Lability in Children and Adolescents with Attention Deficit/Hyperactive Disorder (ADHD): Clinical Correlates and Familial Prevalence, Journal of Child Psychology and Psychiatry, 2010, 51(8).

Sulimani-Aidan Y., Benbenishty R., Future expectations of adolescents in residential care in Israel, Children and Youth Services Review, 2011, 33.

Tiano S., Manor A., Living with ADHD, Dionon, Tel Aviv 2005.

White M., Maps of Narrative Practice, W.W Norton \& Company, New York - London 2007.

Zeidner M., Effective indicators in educational environments, [in:] Guidelines for Renewal of Education Indicators in Israel, Eds. M. Justman, G. Bukobza, Initiative for Applied Research in Education, Israel Academy of Sciences and Humanities, Jerusalem 2010. 